\title{
Effect of Thiosulfate Ions on the Corrosion Behavior of Copper in Simulated Sea Water
}

\author{
A.R. Al Rashed, F.M. Al Kharafi, B. G. Ateya and I. M. \\ Ghayad" \\ Chemistry Department, Faculty of Science, Kuwait University, \\ Kuwait and ${ }^{*}$ Central Metallurgical Research and Development \\ Institute,CMRDI,P.O. Box: 87, Helwan, Cairo,Egypt.
}

\begin{abstract}
ODIUM thiosulfate has a strong effect on the corrosion of copper in salt water. It promotes the anodic dissolution of copper, while the partial cathodic reaction is not affected. It also shifts the free corrosion potential in the active direction by hundreds of $\mathrm{mV}$ and causes extensive corrosion of the metal. The results are substantiated with SEM, EDS and XPS measurements. A mechanism is proposed to start with adsorption of thiosulfate ions on the copper surface followed by a corrosion reaction producing copper sulfide and hydrosulfite ions.
\end{abstract}

Keywords: Copper, Thiosulfate, Polarization, Potentiostatic, SEM, XPS and Passive films.

Copper is a relatively noble metal that possesses an attractive combination of mechanical, electrical and thermal properties ${ }^{(1)}$. It is generally resistant to corrosion, particularly biofoiling. For these reasons, the metal and many of its alloys have long been used as architectural metals ${ }^{(2)}$, in the form of pipes, valves, fittings, radiators, heat exchangers, ..., etc. They have been extensively used in various industries, utilities and marine applications. The corrosion behavior of copper and its alloys has been extensively studied, particularly in salt water ${ }^{(3-11)}$. The stability of copper and its alloys in such environments is attributed to the formation of a protective film of corrosion products containing $\mathrm{Cu}_{2} \mathrm{O}$, $\mathrm{Cu}_{2}(\mathrm{OH})_{3} \mathrm{Cl}$ and oxides of the alloying elements among other products. The above works were concerned with the characterization of the corrosion products, primarily in clean unpolluted media.

Several workers studied the effects of common pollutants on the corrosion behavior of copper and some of its alloys, particularly sulfide ions ${ }^{(12-18)}$. Thiosulfate (TS) is one of the sulfur species that contaminates many industrial environments. It is used as an inorganic fertilizer and as a noncyanide leachant of silver, gold and bismuth ${ }^{(19)}$. It is also encountered in petroleum refining, textile and electroplating, ..., etc. Thiosulfate has been shown to promote the corrosion of some steels and other alloys ${ }^{(22-26)}$. Furthermore, several studies have been performed on the adsorption and oxidation of thiosulfates on various surfaces $^{(27-34)}$.

"E-mail: ighayad@yahoo.com 
Inspite of the extensive use of copper and its alloys in the above industries, the effects of thiosulfates on the corrosion behavior of copper and its alloys have not been adequately addressed or analyzed. The aim of this work is to study the effects of sodium thiosulfate on the electrochemical and corrosion behavior of copper in salt water.

\section{Material and Method}

Electrodes were prepared from $\mathrm{Cu}(99.9 \%)$ obtained from Good fellow. They were polished using $\mathrm{SiC}$ papers successively up to 2400 grits, followed by $0.3 \mu \mathrm{m}$ alumina to acquire a mirror-like finish. A conventional three-electrode cell was used with a $\mathrm{Pt}$ sheet counter electrode and an $\mathrm{Ag} / \mathrm{AgCl}$ reference electrode, $\mathrm{E}=0.197 \mathrm{~V}$ (SHE). Solutions were prepared from deionized water using $\mathrm{NaCl}$ and $\mathrm{Na}_{2} \mathrm{~S}_{2} \mathrm{O}_{3}$ from Fluka. Measurements were performed in $0.58 \mathrm{M} \mathrm{NaCl}$ containing different concentrations of thiosulfate ions $(0.0,0.001,0.005,0.01$, 0.05 and $0.1 \mathrm{M})$ at $25 \pm 1^{\circ} \mathrm{C}$ while the electrolyte was stirred using a magnetic stirrer to provide well defined flow of the reacting species. This electrolyte contains the nominal salt content as sea water. Furthermore, it provides an ionic strength which remains nearly constant independent of the concentration of thiosulfates.

The free corrosion potential was measured as a function of time in $0.58 \mathrm{M}$ $\mathrm{NaCl}$ before and after injecting various concentrations of sodium thiosulfate. The required concentration of thiosulaftae ion was established into the electrolyte by adding a small volume of a concentrated solution and stirring. This process took only few seconds.

Potentiodynamic and potentiostatic polarization experiments were performed on the copper electrodes using Gamry potentiostat. Potentiodynamic curves were measured at a scan rate of $5 \mathrm{mV} \mathrm{s}^{-1}$ starting from $-0.3 \mathrm{~V}$ and ending at $0.7 \mathrm{~V}$ with respect to the corrosion potential. The electrode was preimmersed for $15 \mathrm{~min}$ in the electrolyte before measuring the polarization curves which would allow the $\mathrm{E}_{\mathrm{corr}}$ to reach a steady value. On the other hand, electrochemical impedance measurements (EIS) were carried out under the free corrosion potential.

After potentiostatic experiments, the testing solutions were analyzed for copper ions using inductively coupled plazma (ICP) method. These solutions were also analyzed for sulfite and sulfate ions using liquid chromatography method.

The surfaces of the electrodes were examined using X-ray photoelectron spectroscopy (XPS),VG Scientific 200 spectrometer (U.K), using Mg Ka radiation $(1253.6 \mathrm{eV}$ ) operating at $13 \mathrm{kV}$ and $23 \mathrm{~mA}$ and a scanning electron microscope (SEM, JSM-6300 JEOL).

Egypt. J. Chem. 57, No. 2 (2014) 


\section{Results and Discussion}

\section{Electrochemical testing}

Figure 1 illustrates the polarization curve of copper in $3.5 \% \mathrm{NaCl}$ at $25^{\circ} \mathrm{C}$, measured at a voltage scanning rate of $5 \mathrm{mV} \mathrm{s}^{-1}$. The figure shows the results of five different runs superimposed on each other, indicating good reproducibility. The anodic branch shows a straight line region with a Tafel slope of $59 \mathrm{mV}$. The anodic polarization curve of copper treated in $0.58 \mathrm{M} \mathrm{NaCl}$ shows a Tafel region with a Tafel slope of $59 \mathrm{mV}$, which agrees with the accepted values in the literature $^{(4)}$. This value of Tafel slope is commonly associated with the following reaction:

$$
\mathrm{Cu}_{(\mathrm{s})}+2 \mathrm{Cl}_{(\mathrm{aq})}^{-} \rightarrow \mathrm{CuCl}_{2(\mathrm{aq})}^{-}+\mathrm{e}^{-}
$$

This reaction occurs via a mechanism that includes an initial adsorption step involving the chloride ion ${ }^{(5)}$, i.e.

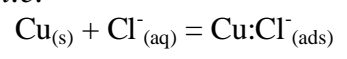

where ${\mathrm{Cu}: \mathrm{Cl}^{-}}_{\text {(ads) }}$ refers to a chloride ion adsorbed on the copper surface. This is followed by a charge transfer step ${ }^{(5)}$, i.e.

$$
\mathrm{Cu}: \mathrm{Cl}^{-}{ }_{\text {(ads) }} \rightarrow \mathrm{CuCl}+\mathrm{e}^{-}
$$

The final step of this reaction leads to the formation of the $\mathrm{CuCl}_{2}^{-}$complex, i.e.

$$
\mathrm{CuCl}+\mathrm{Cl}^{-}=\mathrm{CuCl}_{2}^{-}
$$

Within the Tafel region, the anodic current is clearly dependent on both charge transfer and mass transport. The diffusion of $\mathrm{CuCl}^{-2}$ away from the electrode surface is taken to control the mass transport controlled component of the current ${ }^{(5,35-37)}$.

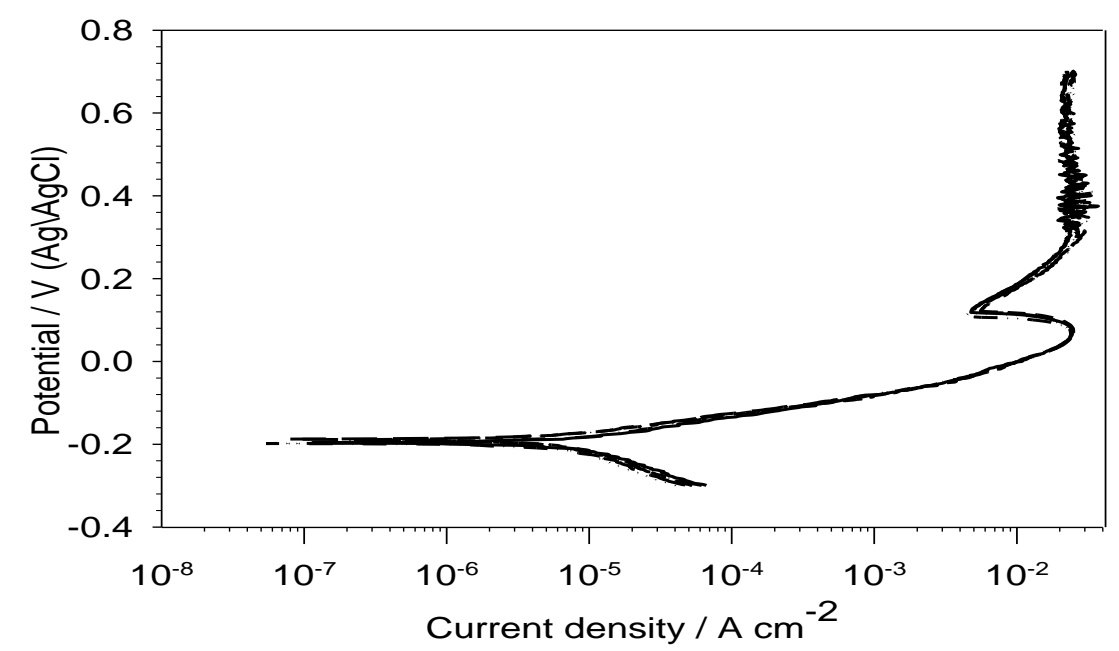

Fig. 1. Potentiodynamic polarization curve of copper in $0.58 \mathrm{M} \mathrm{NaCl}$ at $25^{\circ} \mathrm{C}$ measured at $5 \mathrm{mV} \mathrm{s}^{-1}$. Five different runs are superimposed on each other to show the reproducibility of the results. 
After the Tafel region, the current reaches a maximum peak then decreases to a minimum and subsequently increases to a limiting value. The peak maximum, minimum and limiting current density responses observed are produced as the formation of $\mathrm{CuCl}$ becomes faster than either its complexion by the chloride ion or mass transport of the cuprous dichloride complex to the bulk solution. The apex peak current, therefore, is followed by a current minimum as surface $\mathrm{CuCl}$ coverage reaches its maximum. Further reaction of the copper with chloride ions to form $\mathrm{CuCl}$ is reduced to a rate equals to the rate of $\mathrm{Cl}^{-}$diffusion from the bulk of the electrolyte to the electrode surface ${ }^{(38,39)}$. The cathodic partial reaction is often represented by:

$$
\mathrm{O}_{2}+2 \mathrm{H}_{2} \mathrm{O}+4 \mathrm{e}^{-}=4 \mathrm{OH}^{-}
$$

The resulting $\mathrm{CuCl}_{2}^{-}$is involved in a chemical reaction that leads to the formation of $\mathrm{Cu}_{2} \mathrm{O}^{(5)}$, i.e.

$$
2 \mathrm{CuCl}_{2}^{-}+2 \mathrm{OH}^{-}=\mathrm{Cu}_{2} \mathrm{O}+\mathrm{H}_{2} \mathrm{O}+4 \mathrm{Cl}^{-}
$$

At the corrosion potential the anodic reaction is under mixed control while oxygen reduction is under pure charge transfer control and, as such, the corrosion rate is dependent on mass transport conditions .

Figure 2 illustrates the effect of the concentration of thiosulfate on the free corrosion potential of copper in the chloride medium. Upon injecting the thiosulfates in the medium, the corrosion potential shifts rapidly in the active direction. The magnitude of this shift increases with the concentration of thiosulfate, from about $270 \mathrm{mV}$ at $0.001 \mathrm{M}$ to about $500 \mathrm{mV}$ at $0.1 \mathrm{M}$. Subsequent to this rapid shift, the corrosion potential remains fairly constant indicating the approach of a steady state process. A shift of the corrosion potential in the active direction reveals a greater tendency for corrosion.

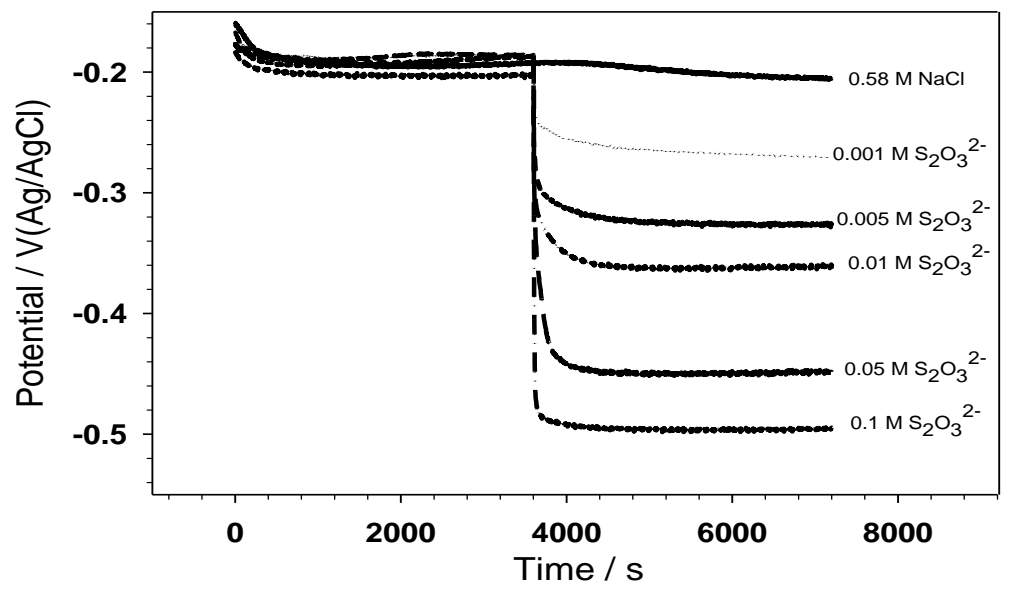

Fig. 2. Variation of the corrosion potential of copper with time in $0.5 \mathrm{M} \mathrm{NaCl}$ before and after injection of various concentrations of sodium thiosulfate.

Egypt. J. Chem. 57, No. 2 (2014) 
The effect of the concentration of thiosulfate on the polarization curves of copper in the chloride medium is shown in Fig. 3. The figure reveals a strong promoting effect of thiosulfate on the rate of anodic dissolution and a much less significant effect on the cathodic partial reaction. As the concentration of thiosulfate increases, the anodic current increases by orders of magnitude while the free corrosion potential shifts in the active direction by hundreds of $\mathrm{mV}$ depending on the extent of the increase in the concentration of thiosulfate.

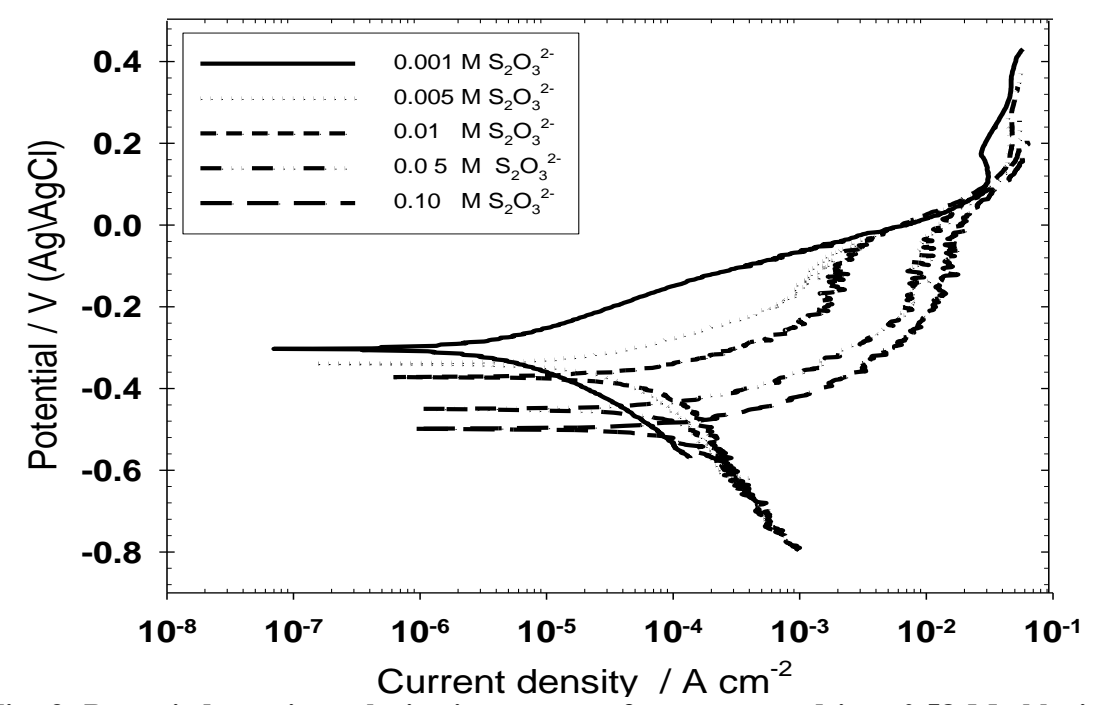

Fig. 3. Potentiodynamic polarization curves of copper tested in e $0.58 \mathrm{M}$ chloride medium containing different concentration of sodium thiosulfate at $25^{\circ} \mathrm{C}$ and $5 \mathrm{mV} \mathrm{s}^{-1}$.

Thiosulfates are known to adsorb on many substrates ${ }^{(34)}$ and indeed on copper surfaces ${ }^{(40,41)}$. The process can be represented by the following equation:

$$
\mathrm{Cu}_{(\mathrm{s})}+\mathrm{S}_{2} \mathrm{O}_{3}{ }^{2-}{ }_{(\mathrm{aq})}=\mathrm{Cu}: \mathrm{S}_{2} \mathrm{O}_{3}{ }^{2-} \text { (ads) }
$$

where $\mathrm{Cu}: \mathrm{S}_{2} \mathrm{O}_{3}{ }^{2-}$ (ads) refers to thiosulfate ions adsorbed on the copper surface. The equilibrium of Eq.7 can be described using many isotherms. It has been described using the Langmuir isotherm, i.e.

$$
\theta_{\mathrm{S}_{2} \mathrm{O}_{3}}=\frac{\mathrm{Kc}}{1+\mathrm{Kc}}
$$

where $\theta_{\mathrm{S} 2 \mathrm{O} 3}$ is the degree of coverage of the surface with adsorbed thiosulfate, $\mathrm{c}$ is its concentration in the electrolyte and $\mathrm{K}$ is the equilibrium constant of reaction 7 .

The above relation is nonlinear. It can be simplified under some conditions. For the case of weak adsorption $\left(\theta_{\mathrm{TS}}<<1\right), \theta_{\mathrm{S} 2 \mathrm{O} 3} \approx \mathrm{Kc}$. On the other hand, for strong adsorption, $\mathrm{Kc}>>1$, hence $\theta_{\mathrm{S} 2 \mathrm{O} 3} \approx 1$. 
The above results can be used to obtain a reaction order (r), which measures the effect of thiosulfate concentration on the rate of dissolution of copper. The reaction order ( $r$ ) can be obtained from the slope of a logarithmic plot between the current at a certain potential (I) and the concentration of the thiosulfate, c, i.e.

$$
r=\partial \log I / \partial \log c
$$

Figure 4 illustrates such a plot at potentials of -0.1 and $0.0 \mathrm{~V}$. The results give straight lines with slope of 0.77 and 0.2 , respectively indicating that $r$ decreases as the potential becomes more noble. This reaction order is an apparent value with respect to the bulk concentration of thiosulfate, c. In reality, however, the reacting ions are adsorbed on the electrode surface at a degree of coverage $\left(\theta_{\mathrm{S} 2 \mathrm{O}^{--}}\right)$. The current at each potential in Fig. 5 is the sum of two components, i.e.

$$
\mathrm{I}=\mathrm{I}_{\mathrm{S} 2 \mathrm{O} 3}{ }^{--}+\mathrm{I}_{\mathrm{Cl}}^{-}
$$

where $\mathrm{I}_{\mathrm{S} 2 \mathrm{O} 3}{ }^{--}$and $\mathrm{I}_{\mathrm{Cl}}{ }^{-}$refer to the currents generated from the electrode areas covered with adsorbed thiosulfate and adsorbed chloride ions, respectively.

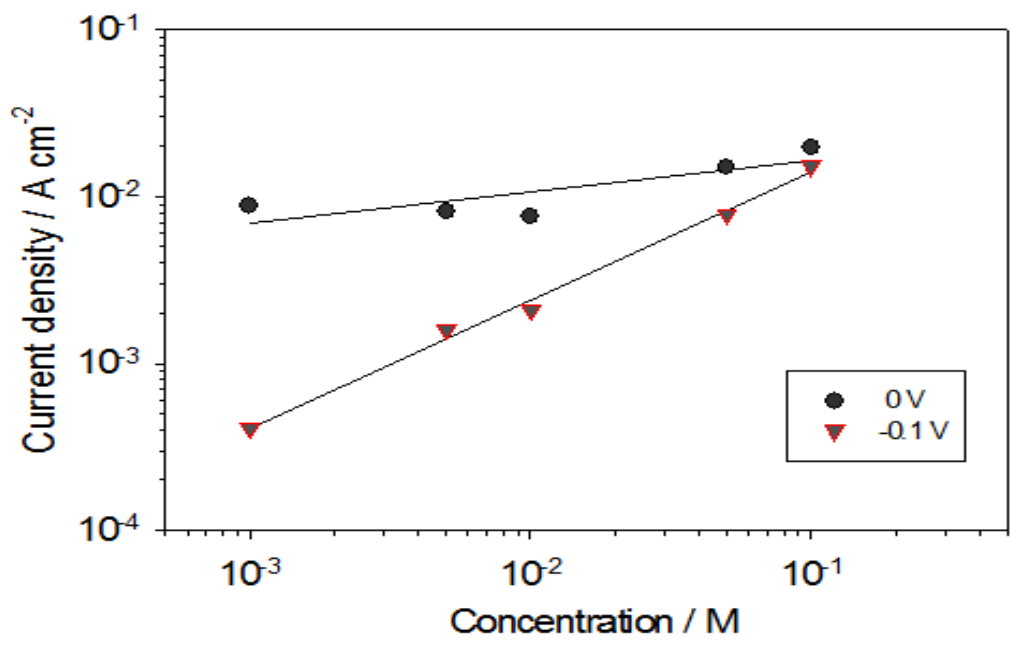

Fig. 4. Logarithmic plot between the current and the concentration of sodium thiosulfate in the electrolyte at two different potentials. The slope calculated from each line give the reaction order at the given potential.

The results of Fig. 3 show that the current in the presence of thiosulfate $\left(\mathrm{I}_{\mathrm{TS}}\right)$ is orders of magnitude greater than $\left(\mathrm{I}_{\mathrm{Cl}}{ }^{-}\right)$. Hence it can be assumed that the current is predominantly resulting from the thiosulfate covered area of the electrode surface, i.e.

$$
\mathrm{I} \approx \mathrm{I}_{\mathrm{S} 2 \mathrm{O} 3}{ }^{--}
$$

In the activation controlled region, the current is related to the potentioal by: 


$$
\mathrm{I}=\mathrm{nF} \theta_{{\mathrm{S} 23^{2-}}^{2-}} \mathrm{k}^{\circ} \exp \left(\frac{\alpha \mathrm{nFE}}{\mathrm{RT}}\right)
$$

where $\mathrm{n}$ is the number of electrons, $\mathrm{F}$ is the Faraday constant, $\mathrm{k}^{\circ}$ is the standard rate constant of the charge transfer step (at a certain reference potential), $\alpha$ is the charge transfer coefficient, $\mathrm{E}$ is the electrode potential, $\mathrm{R}$ is the universal gas constant, and $\mathrm{T}$ is the absolute temperature. At constant potential, an electrochemical rate constant $\left(\mathrm{k}_{\mathrm{ec}}\right)$ can be defined at a certain potential $(\mathrm{E})$, as follows:

$$
\mathrm{k}_{\mathrm{ec}}=\mathrm{k}^{\mathrm{o}} \exp \left(\frac{\alpha \mathrm{nFE}}{\mathrm{RT}}\right)
$$

Substituting with the Eqs. 8 \& 13 in Eq. 12, one obtains:

$$
\mathrm{I}=\mathrm{nF} \frac{\mathrm{Kc}}{1+\mathrm{Kc}} \mathrm{k}_{\mathrm{ec}}
$$

Equation 14 relates the current to the concentration of thiosulfate, at a certain potential. Clearly the relation between current and thiosulfate concentration is nonlinear. It can be simplified under two limiting cases.

\section{a)Low surface coverage}

Under this condition, where $\theta \ll<1, \mathrm{Kc} \ll 1$. Hence

$$
\mathrm{I}=\mathrm{nF}(\mathrm{K} c) \mathrm{k}_{\mathrm{ec}}
$$

Eq. 15 indicates that, under the condition of weak adsorption, the current depends on the thiosulfate concentration raised to power of one, i.e. the reaction order is one. The reaction order of 0.77 obtained at $-0.1 \mathrm{~V}(\mathrm{Ag} / \mathrm{AgCl})$ indicates that the adsorption of thiosulfate under this condition is closer to the limiting case of low surface coverage.

\section{b) High surface coverage}

Under this condition, $\mathrm{Kc} \gg>1$. Hence Eq. 18 is simplified to:

$$
I=n F k_{e c}
$$

Eq. 16 reveals zero order dependence of the current on the concentration of thiosulfate. This is the case observed at high potential. A reaction order of 0.2 at $0 \mathrm{~V}(\mathrm{Ag} / \mathrm{AgCl})$ indicates high surface coverage of thiosulfates under this condition.

Figure 5 shows the current transients produced by the copper electrode hold at $-0.15 \mathrm{~V}$ before and after injection of various concentrations of thiosulfate. Note the sharp increase of current upon injection of the thiosulfate. The extent of the current jump increases with the concentration of thiosulfate. 


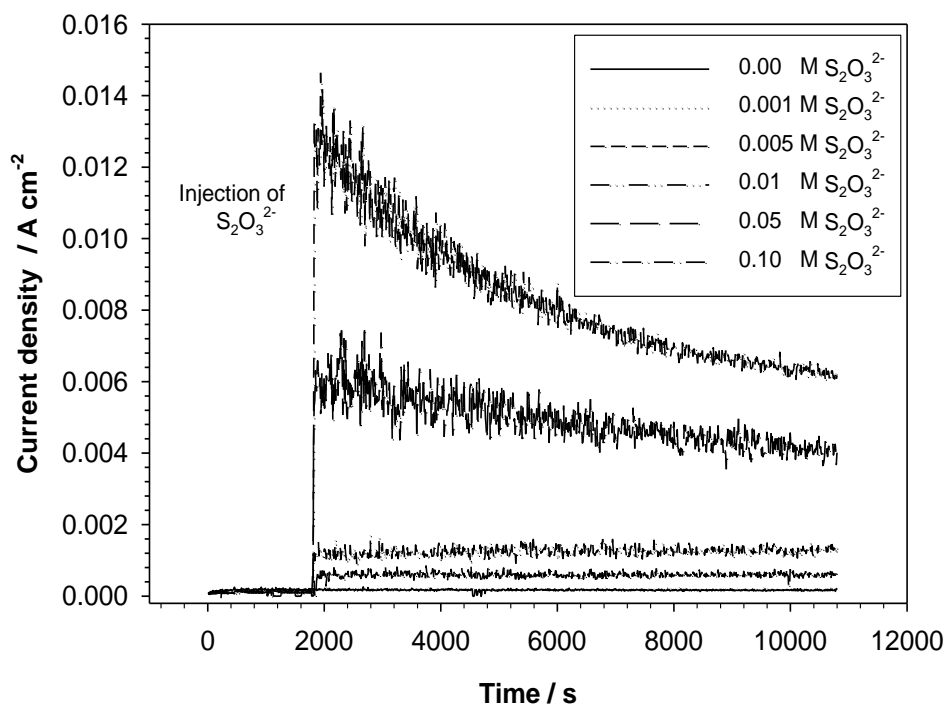

Fig. 5. Current transients of the copper electrode before and after injection of various concentrations of sodium thiosulfate into the electrolyte $(0.58 \mathrm{M}$ $\mathrm{NaCl})$. The copper electrode was potentiostated at $-\mathbf{0 . 1 5} \mathrm{V}(\mathrm{Ag} / \mathrm{AgCl})$.

Polarization resistance was measured using electrochemical impedance spectroscopy (EIS). EIS spectra were measured before and after the injection of various concentrations of thiosulfate. EIS spectra are shown in Figure 6. Analysis of these spectra yields the polarization resistance $\left(R_{p}\right)$ which is inversely proportional to the corrosion rate, i.e.

$$
\mathrm{R}_{\mathrm{p}}=\frac{\beta_{\mathrm{a}} \beta_{\mathrm{c}}}{2.3\left(\mathrm{~b}_{\mathrm{a}}+\mathrm{b}_{\mathrm{c}}\right) \mathrm{I}_{\mathrm{corr}}} \mathrm{mpy}
$$

where $\beta_{\mathrm{a}}$ and $\beta_{\mathrm{c}}$ are the anodic and cathodic Tafel slopes while $\mathrm{I}_{\text {corr }}$ is the corrosion current. $I_{\text {corr }}$ can be used to calculate the corrosion rate using the following equation:

$$
\mathrm{CR}=\frac{\mathrm{I}_{\text {corr }} \text { EW } 1.288 \times 10^{5}}{\mathrm{~d} \mathrm{~A}}
$$

where EW is the equivalent weight of the corroded species $(31.77$ for $\mathrm{Cu}), \mathrm{d}$ is the density of the corroded metal in $\mathrm{g} / \mathrm{cm}^{3}\left(8.96 \mathrm{~g} \mathrm{~cm}^{-3}\right.$ for $\left.\mathrm{Cu}\right)$ and $\mathrm{A}$ is the area in $\mathrm{cm}^{2}\left(0.196 \mathrm{~cm}^{2}\right)$. Results are summarized in Table 1 . 

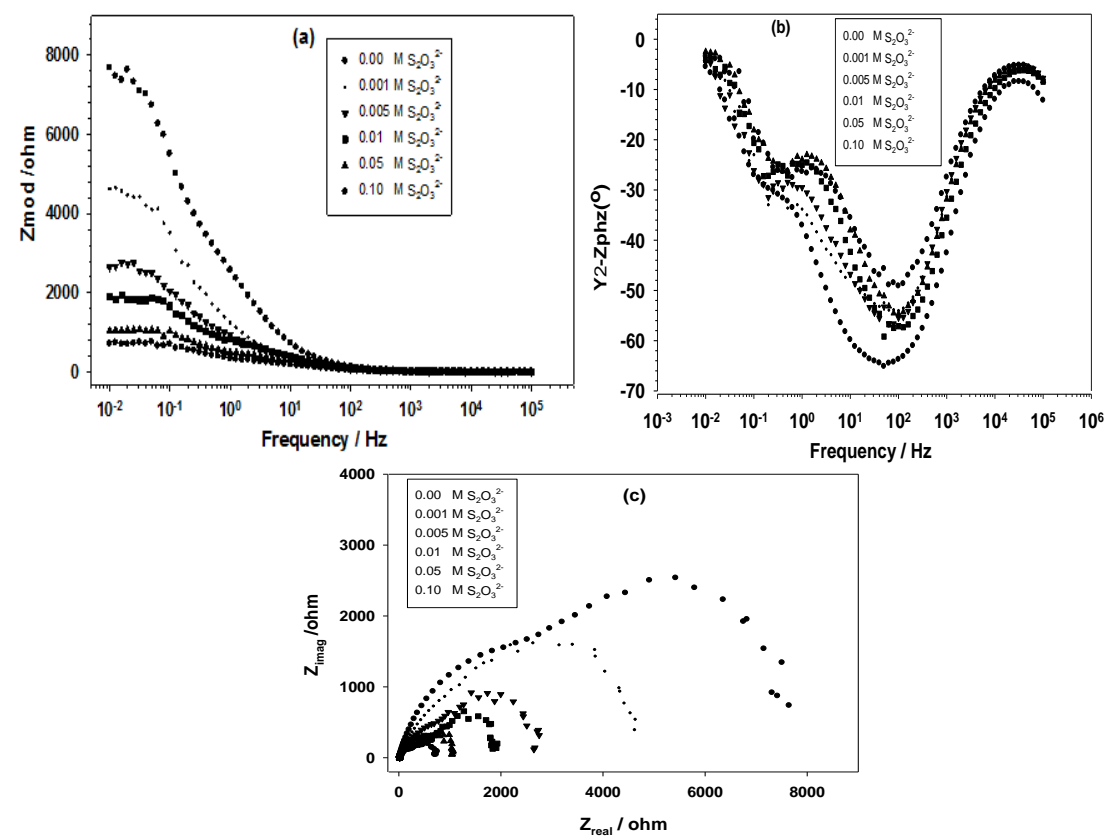

Fig. 6. Electrochemical impedance spectra of the copper electrode treated in the presence of various concentrations of sodium thiosulfate. The results were obtained one hour after injection of thiosulfate. (a) Bode modulus plots (b) Bode phase angle (c) Nyquist plots.

TABLE 1. The atom percent of sulfur (determined by EDS) in different corroded regions shown in Fig.7a.

\begin{tabular}{|c|c|c|c|c|}
\hline Regions & A & B & C & D \\
\hline Atom \% S & 0.47 & 3.01 & 0.21 & 1.79 \\
\hline
\end{tabular}

The injection of thiosulfate decreases the polarization resistance and hence increases the corrosion rate. The extent of decrease in the polarization resistance and the increase in corrosion rate is directly proportional to the thiosulfate concentration. For example, in the absence of thiosulfate, the impedance of the interface (the layer formed between the metal and the electrolyte) is about 1503 ohm $\mathrm{cm}^{2}$ while the corrosion rate is $5.22 \mathrm{mpy}$. The corresponding values of $\mathrm{R}_{\mathrm{p}}$ in the presence of 0.01 and $0.1 \mathrm{M}$ thiosulfate are 372.4 and $137.8 \mathrm{ohm} \mathrm{cm}^{2}$ while the corrosion rate values are 60.6 and $183.2 \mathrm{mpy}$, respectively. 
Surface characterization of the corroded samples

The corroded surfaces were examined using scanning electron microscopy (SEM), Electron Dispersion Spectroscopy (EDS), and X-ray Photoelectron Spectroscopy (XPS). Figure7a shows the image of the copper surface that was potentiostated in the presence of $0.05 \mathrm{M}$ thiosulfate at $-0.15 \mathrm{~V}$ for $3 \mathrm{hr}$.
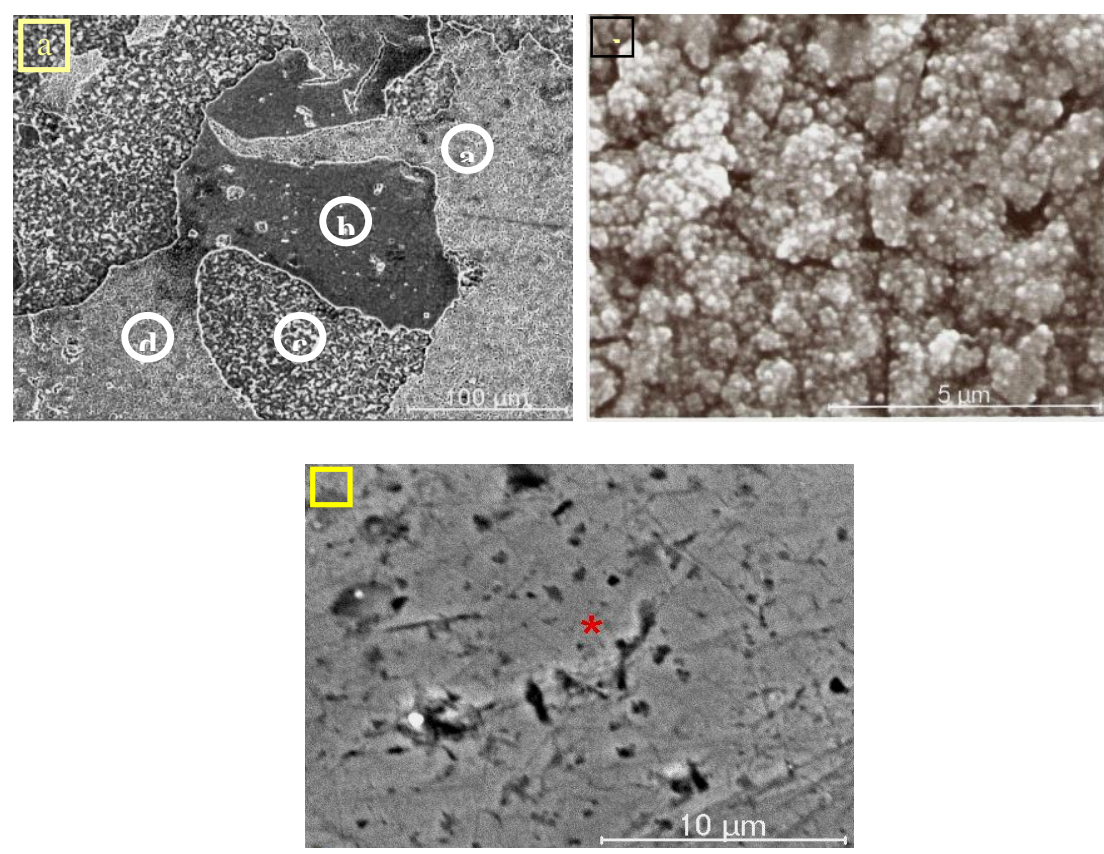

Fig. 7. SEM images of a copper surface treated for $3 \mathrm{hr}$ under the following conditions: a) In $0.58 \mathrm{M} \mathrm{NaCl}$ containing $0.05 \mathrm{M} \mathrm{S}_{2} \mathrm{O}_{3}{ }^{2-}$ at a potential of $0.15 \mathrm{~V}$. b) In $0.58 \mathrm{M} \mathrm{NaCl}$ containing $0.05 \mathrm{M} \mathrm{S}_{2} \mathrm{O}_{3}{ }^{2-}$ at the free corrosion potential. c) In $0.58 \mathrm{M} \mathrm{NaCl}$ containing no $\mathrm{S}_{2} \mathrm{O}_{3}{ }^{2-}$ at $-0.15 \mathrm{~V}$.

Copper was also corroded, under free corrosion in the presence of $0.05 \mathrm{M}$ sodium thiosulfate for $3 \mathrm{hr}$ (Fig.7b). Figure 7c shows the copper surface potentiostated at $-0.15 \mathrm{~V}$ in $0.58 \mathrm{M} \mathrm{NaCl}$ in the absence of thiosulfate. The corrosion attack on copper is much more pronounced in the presence of thiosulfate. Note the heterogeneous appearance of the corroded surface.

The above figures reveal the presence of massive amounts of granular porous corrosion products on the surface, which are caused by the presence of thiosulfates in the salt water. The corroded copper surfaces were also analyzed 
using EDS and XPS. The EDS spectra indicate that these corrosion products include substantial amounts of sulfur.

Table 1 shows sulfur amounts in different regions of Fig.7a. These corroded regions are also heterogeneous in their sulfur content in addition to being heterogeneous in their appearance under the SEM microscope.

The XPS spectrum in Fig. 8 was obtained from a surface that was kept for 3 hr under free corrosion at $-0.15 \mathrm{~V}(\mathrm{Ag} / \mathrm{AgCl})$ in the presence of $0.05 \mathrm{M}$ thiosulfate. XPS spectra were also measured in the presence of various concentrations of thiosulfate, under free corrosion and at $-0.15 \mathrm{~V}(\mathrm{Ag} / \mathrm{AgCl})$. A sharp $S_{2 P}$ peak at a binding energy of $161.5 \pm 0.3 \mathrm{eV}$ was shown in both cases. This peak is characteristic of sulfide ions ${ }^{(41)}$. Some authors have attributed a similar binding energy to elemental sulfur adsorbed on the copper surface, at monolayer or submonolayer levels ${ }^{(15)}$. Note the presence of a weaker $S_{2 p}$ peak at about $168 \mathrm{eV}$ in the case of copper treated at anodic potential. This high binding energy is associated with oxygen bearing sulfur species, such as sulfates or sulfites. The features of the reaction mechanism point to the formation of sulfite ions among the reaction products.
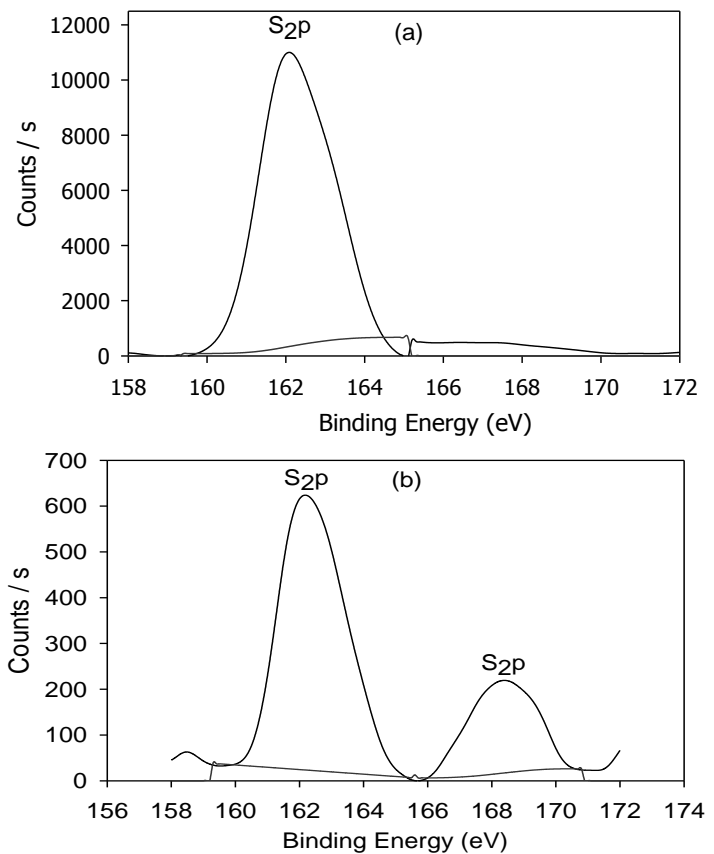

Fig. 8. XPS spectrum of the copper electrode after being potentiostated under free corrosion (a) and at $-0.15 \mathrm{~V}$ (b) for $3 \mathrm{hr}$ in the presence of $0.05 \mathrm{M}$ sodium thiosulfate.

Egypt. J. Chem. 57, No. 2 (2014) 


\section{Characterization of the corrosion reaction products}

The electrolytes of potentiostatic tests were also analyzed to find the changes in the concentrations of dissolved sulfates, sulfites and copper ions.

The results are summarized in Table 2. Inspection of these results reveals some important findings:

1. Under free corrosion conditions, a small concentration of copper ions equals $0.6 \mathrm{ppm}(\mathrm{mg} / \mathrm{l})$ was detected in the electrolyte, while the concentrations of sulfates $\left(\mathrm{SO}_{4}{ }^{2-}\right)$, and sulfites $\left(\mathrm{SO}_{3}{ }^{2-}\right)$ remain essentially the same as those in the blank electrolyte. However, it was shown that the copper surface was corroded and covered with a black layer of $\mathrm{CuS}$. This indicates that under free corrosion conditions, the main reaction product is the formation of $\mathrm{CuS}$.

2. Under potentiostatic tests for $6 \mathrm{hr}$ at $-0.15 \mathrm{~V}$, the concentrations of dissolved ions increase as follows:

a) Copper ions increase to $133 \mathrm{ppm}$ (compared to about $0.1 \mathrm{ppm}$ in the blank electrolyte).

b) The sulfate $\left(\mathrm{SO}_{4}{ }^{2-}\right)$ ions increase to $74.5 \mathrm{ppm}$ (compared to about $30 \mathrm{ppm}$ in the blank electrolyte).

c) The sulfite $\left(\mathrm{SO}_{3}{ }^{2-}\right)$ ions increase to $352 \mathrm{ppm}$ (compared to $120 \mathrm{ppm}$ in the blank electrolyte). This clearly indicates that the increase of the concentration of copper ions is associated with increase of the concentrations of sulfite and sulfate ions.

3. Under potentiostatic tests for $12 \mathrm{hr}$ at $-0.15 \mathrm{~V}$, much greater increases in the concentrations of copper and sulfite ions were observed. The concentration of dissolved copper ions increased to $318 \mathrm{ppm}$ (compared to about $0.1 \mathrm{ppm}$ in the blank electrolyte), the sulfate $\left(\mathrm{SO}_{4}{ }^{2-}\right)$ ions increased to $97 \mathrm{ppm}$ (compared to about $30 \mathrm{ppm}$ in the blank electrolyte) while the sulfite $\left(\mathrm{SO}_{3}{ }^{2-}\right)$ ions increased to $878 \mathrm{ppm}$ (compared to $120 \mathrm{ppm}$ in the blank electrolyte). The increase in the concentrations of copper, sulfite, and sulfate ions is associated with increase in the amount of charge that passed through the circuit during the test. However, quantitative correlation of these numbers is quite difficult.

The above results indicate that the electrochemical dissolution (corrosion) of copper in the thiosulfate polluted medium produces several products, i.e. solid adherent $\mathrm{CuS}$, dissolved copper, sulfite and sulfate species. 
TABLE 2. Summary of the concentrations (c/ppm) of the various ionic species measured in the electrolyte after the corrosion of copper for various times under free corrosion and under controlled potential. $Q$ is the amount of charge passed during the potentiostatically controlled test.

\begin{tabular}{|l|c|c|c|c|}
\hline Condition & $\begin{array}{c}\mathrm{Cu}^{+2} \\
(\mathbf{p p m})\end{array}$ & $\begin{array}{c}\mathrm{SO}_{4}{ }^{2-} \\
(\mathbf{p p m})\end{array}$ & $\begin{array}{c}\mathrm{SO}_{3}{ }^{2-} \\
(\mathbf{p p m})\end{array}$ & $\mathrm{Q} / \mathrm{C}$ \\
\hline Blank electrolyte & $<\mathbf{0 . 1}$ & $\mathbf{3 0 . 3}$ & $\mathbf{1 2 0}$ & - \\
\hline At $\mathbf{E}_{\text {corr }}$ for 6h & $\mathbf{0 . 6}$ & $\mathbf{3 0 . 5}$ & $\mathbf{1 2 0}$ & - \\
\hline At $\mathbf{E}_{\text {corr }}$ for 12h & $\mathbf{1 . 1}$ & 33.7 & 123 & - \\
\hline Potentiostatic for 6h at -0.15 V & $\mathbf{1 3 3 . 3}$ & $\mathbf{7 4 . 5}$ & 352 & $\mathbf{2 5 . 3 ~ C}$ \\
\hline Potentiostatic for 12h at -0.15 V & $\mathbf{3 1 8 . 4}$ & $\mathbf{9 7}$ & $\mathbf{8 7 8}$ & $\mathbf{3 9 . 6} \mathrm{C}$ \\
\hline
\end{tabular}

\section{Proposed mechanism}

The adsorption of thiosulfate was described in terms of Langmuir isotherm. This offered an interpretation of the observed reaction orders. The behavior of thiosulfate is actually more complex than the simple picture of a Langmuir adsorption. This is due to the nature of the thiosulfate ion. The two sulfur atoms in the thiosulfate ion $\left(\mathrm{S}_{2} \mathrm{O}_{3}{ }^{2-}\right)$ are not equivalent. The structural formula of thiosulfate ion is shown in Fig.9. Oxidation states of the two sulfur atoms and the three oxygen atoms constituting thiosulfate ions are as follows:

- The oxygen atoms would have oxidation numbers of -2 .

- The central sulfur would have an oxidation number of +6 .

- The normal bonding sulfur atom would have an oxidation number of -2 .

While the central sulfur atom is well bonded to the three oxygen atoms, the peripheral sulfur atom is weakly attached to the central sulfur atom via a weak, and hence fairly long, bond. The bond length of S-0 bond is 147 picometer (1.47 $\mathrm{A}^{\mathrm{o}}$ ) compared to $201 \mathrm{pm}\left(2.01 \mathrm{~A}^{\mathrm{o}}\right)$ obtained for S-S bond. Consequently both sulfur atoms behave differently towards the copper surface.

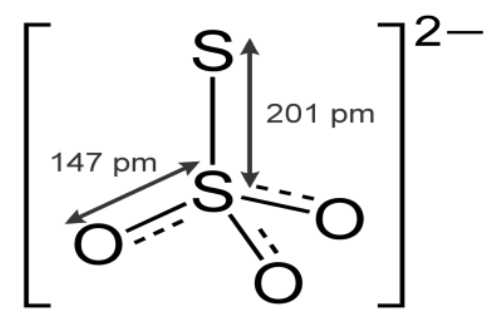

Fig. 9. Structural formula of thiosulfate ion. 
Based on the above explanation, the adsorption of thiosulfate is described in terms of dissociative adsorption. The mechanism of thiosulfate adsorption and oxidation is schematically presented as follows:

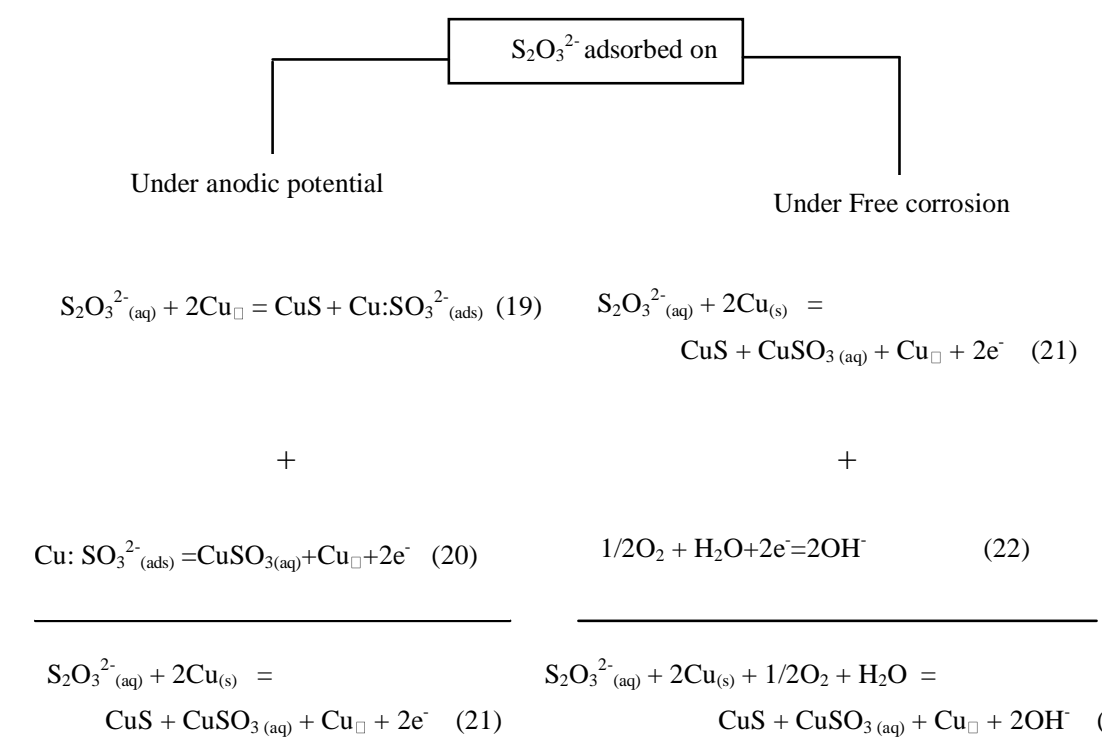

Eq. 19 represents the dissociative adsorption of thiosulfate on copper; where $\mathrm{Cu}_{\square}$ refers to the active adsorption sites on the copper surface, while $\mathrm{Cu}_{\mathrm{SO}} \mathrm{SO}_{3}{ }^{2-}$ (ads) refers to adsorbed sulfite ions. The sulfite covered areas of the copper electrode undergo a rapid anodic dissolution reaction producing $\mathrm{CuSO}_{3}$ and a fresh active site $\mathrm{Cu}_{\square}$ (eq. 20). The overall process is the sum of both equations (eq. 21).

Under free corrosion conditions, the partial anodic reaction is presented by Eq.21 while the partial cathodic reaction can be presented by the reduction of oxygen according to Eq.22. The overall corrosion reaction under free corrosion conditions on these active sites can be represented by the sum of Eq. 21 and 22 (Eq. 23). This indicates that under free corrosion, the reaction product includes $\mathrm{CuS}$, sulfite and copper ions. Under anodic potential, reaction 20 occurs at much higher rate than the case under free corrosion which is supported by the appearance of $S_{2 p}$ peak characteristic of sulfite ion.

\section{Conclusions}

- Sodium thiosulfate shifts the free corrosion potential of copper to more active values by hundred of $\mathrm{mV}$ which reflects a greater tendency to corrosion. The extent of this shift depends on the concentration of thiosulfate.

- Sodium thiosulfate shows a strong promoting effect on the rate of the anodic dissolution of copper by increasing the anodic current by orders of magnitude.

Egypt. J. Chem. 57, No. 2 (2014) 
The presence of thiosulfate results in the increase of the corrosion rate to a large extent depending on its concentration.

- Analysis of the electrolytes revealed that the corrosion of copper in the presence of thiosulfate results in a significant increase in the concentrations of sulfite and copper ions.

- The SEM images revealed the presence of massive amounts of porous heterogeneous corrosion products on the copper surfaces corroded in the presence of sodium thiosulfate under various potentials and thiosulfate concentrations. EDS analysis revealed the presence of large amounts of sulfur on the same regions of the corroded surface and their absence in other regions The XPS spectra of the corroded copper surfaces revealed a strong $S_{2 p}$ peak at a binding energy of $161.3 \mathrm{eV}$ which is attributed to sulfide ions. XPS revealed also a weaker $S_{2 p}$ peak at about $168 \mathrm{eV}$, characteristic of sulfites, in the case of copper treated at anodic potential.

- The reaction mechanism of thiosulafte with copper was proposed depending on its dissociative adsorption and oxidation on copper.

Acknowledgements: The authors acknowledge the support of this work by the Research Administration of Kuwait University, Grant number SC06/07 and GS01/01 and the service provided by the Unit of Electron Microscope.

\section{References}

1. Giles, F.C., Mechanical, Chemical and Physical Properties of Metals, in: H. E Boyer, T. L. Gall. (Ed) Metals Handbook, Desk Edition. American. Society for Metals, Metals Park, OH, p.2 (1985).

2. William Zahner, L., Architectural Metals, John Wiley \& Sons, Inc, New York, p. 92(1995).

3. Drach, A., Tsukrov, I., DeCew, J., Aufrecht, J., Grohbauer, A. and Hofmann, U., Field studies of corrosion behaviour of copper alloys in natural seawater. Corros. Sci. 76, 453 (2013).

4. Fredj, N., Kolar, J.S., Prichard, D.M. and Burleigh, T.D., Study of relative color stability and corrosion resistance of commercial copper alloys exposed to hand contact and synthetic hand sweat. Corros. Sci. 76, 415 (2013).

5. Sayed, S.M. , Ashour, E.A. and Youssef, G.I. , Effect of sulfide ions on the corrosion behavior of $\mathrm{Al}$-brass and $\mathrm{Cu}-10 \mathrm{Ni}$ alloys in salt water. Mater. Chem. Phys. 78(3), 825 (2003).

6. Nikolaos, D., Alexopoulos, Charis, J., Dalakouras, Panagiotis Skarvelis and Stavros, K., Kourkoulis, Accelerated corrosion exposure in ultra thin sheets of 2024 aircraft aluminium alloy for GLARE applications. Corros. Sci. 55, 289 (2012). 
7. Abd El-Hafez, G. M. and Badawy, W. A. , Use of cysteine, N-acetyl cysteine and methionine as environmentally friendly corrosion inhibitors for $\mathrm{Cu}-10 \mathrm{Al}-5 \mathrm{Ni}$ alloy in neutral chloride solutions. Electrochim. Acta, 108, s. 860 (2013).

8. Rosalbino, F., Carlini, R. , Soggia, F., Zanicchi, G. and Scavino, G., Influence of rare earth metals addition on the corrosion behaviour of copper in alkaline environment. Corros. Sci. 58,139 (2012).

9. Ha, H., Taxen, C. and Williams, K. and Scully, J., Effects of selected water chemistry variables on pit propagation kinetics in copper: Connection between corrosion product identity, properties and pit growth behavior. Electrochim. Acta, $\mathbf{5 6}$ (17), 6165(2011).

10. Metikoš-Huković, M., Babić, R., Škugor, I. and Gruba, Z., Copper-nickel alloys modified with thin surface films: Corrosion behavior in the presence of chloride ions. Corros. Sci. 53 (1), 347 (2011).

11. Finsgar, M., EQCM and XPS analysis of 1,2,4-triazole and 3-amino-1,2,4-triazole as copper corrosion inhibitors in chloride solution. Corros. Sci. 77, 350 (2013).

12. Mountassir, Z. and Srhiri, A., Electrochemical behaviour of $\mathrm{Cu}-40 \mathrm{Znin} 3 \% \mathrm{NaCl}$ solution polluted by sulphides: Effect of aminotriazole. Corros. Sci. 49, 1350 (2007).

13. Yuan, S.J. and Pehkonen, S.O., Surface characterization and corrosion behavior of $70 / 30 \mathrm{Cu}-\mathrm{Ni}$ alloy in pristine and sulfide-containing simulated seawater. Corros. Sci. 49, 1276 (2007).

14. Rahmouni, K., Hajjaji, N., Keddam, M., Srhiri, A. and Takenouti, H., The inhibiting effect of 3-methyl 1,2,4-triazole 5-thione on corrosion of copper in 3\% $\mathrm{NaCl}$ in presence of sulphide. Electrochim. Acta, 52, 7519 (2007).

15. Xu, H.C., Seshadri, S.R. and Kelber, J.A., Sulfur catalyzed electrochemical oxidation of $\mathrm{Cu}$ : A combined ultrahigh vacuum electrochemical study. $J$. Electrochem. Soc. 146, 1762 (1999).

16. Alhajji, J. N. and Reda, M. R., The conflicting roles of complexing agents on the corrosion of copper - nickel alloys in sulfide polluted seawater. J. Electrochem. Soc. 141,1432 (1994).

17. Vazquez, M. and De Sanchez, S.R., Influence of sulphide ions on the cathodic behaviour of copper in $0.1 \mathrm{M}$ borax solution. J. Appl. Electrochem. 28, 1383 (1998).

18. Zhang, D., Gao, L. and Zhou, G., Inhibition of copper corrosion by bis-(1benzotriazolymethylene)-(2,5-thiadiazoly)-disulfide in chloride media. Appl. Surf. Sci. 225, 287(2004).

19. Ficeriova, J., Balaz P. and Villachica, C. L. , Thiosulfate leaching of silver, gold and bismuth from a complex sulfide concentrates. Hydrometallurgy, 77, 35(2005). 
20. Chen, Y.Y., Liou, Y.M., Shin, H.C., Wang, L.H. and Oung, J.C., Stress corrosion cracking of type 321 stainless steels under simulated petrochemical conditions containing thiosulfate and chloride. Corrosion, 62, 781 (2006).

21. Miranda, E., Bethencourt, M., Botana, F.J. , Cano, M.J., Sánchez-Amaya, J.M., Corzo, A. , García de Lomas, J., Fardeau, M.L. and Ollivier, B. , Biocorrosion of carbon steel alloys by an hydrogenotrophic sulfate-reducing bacterium Desulfovibrio capillatus isolated from a Mexican oil field separator. Corros. Sci. 48, 217(2006).

22. Eric, G. Webb and Richard, C. Alkire, Pit initiation at single MnS inclusions in stainless steel, Part I: Microelectrochemical measurements. J. Electrochem. Soc. 149, B272 (2002).

23. Gomez-Duran, M. and Macdonald, D. D. , Stress corrosion cracking of sensitized Type 304 stainless steel in thiosulfate solution: I. Fate of the coupling current. Corros. Sci. 45, 1455(2003).

24. Hazlewood, P.E. , Singh, P.M. and Hsieh, J.S. , Corrosion, 62, 7652 (2006).

25. Yang, I. J., Corrosion, 49, 576 (1993).

26. Mulford, S. J. and Tromans, D., Corrosion, 44, 891 (1988).

27. Shon, Y.S., M.Gross, S., Dawson, B., Porter, M. and Murray, R.W., Alkanethiolate-protected gold clusters generated from sodium S-dodecylthiosulfate (bunte salts). Langmuir, 16, 6555 (2000).

28. Jung, Ch., Dannenberger, O., Yue, X., Buck, M. and Grunze, M., Self-assembled monolayers from organosulfur compounds: A comparison between sulfides, disulfides, and thiols. Langmuir, 14, 1103(1998).

29. Lusk, A. T. and Jennings, G. K., Characterization of self-assembled ... formed from sodium s-alkyl thiosulfates on copper. Langmuir, 17, 7830 (2001).

30. Srinivasan, R. and Suni, I. I., Differential capacitance studies of the specific adsorption of. thiosulfate on Ag. J. App. Electrochem. 28, 993(1998).

31. Vlckova, M., Steparek, J. and Turpin, P., Probing of porphyrin surface chemistry in systems with laser-ablated ag nanoparticle hydrosol: Role of thiosulfate anions. Langmuir ,21 2956(2005).

32. Protopopoff, E. and Marcus, P., Potential-pH diagrams for sulfur and hydroxyl adsorbed on copper surfaces in water containing sulfides, sulfites or thiosulfates. Corros. Sci. 45, 1191(2003).

33. Degenhardt, J. and McQuillan, A. J., In situ ATR-FTIR spectroscopic study of adsorption of perchlorate, sulfate, and thiosulfate ions onto chromium(III) oxide hydroxide thin films. Langmuir, 15, 4595(1999).

34. Laiho, T., Lukkari, I., Meretoja, M., Laajalehto, K. , Kankare, J. and Leiro, J.A., Chemisorption of alkyl thiols and S-alkyl thiosulfates on Pt (111) and polycrystalline platinum surfaces. Surf Sci. 584, 83(2005).

35. Moreau, A., Etude du mecanisme d'oxydo-reduction du cuivre dans les solutions chlorurees acides-I. Systeme $\mathrm{Cu} / \mathrm{Cu} \mathrm{Cl}^{-}$. Electrochim Acta, 26,497 (1981). 
36. De Sanchez, S.R. and Schiffrin, D.J. , The use of high speed rotating disc electrodes for the study of erosion-corrosion of copper base alloys in sea water. Corros Sci. 28 141, (1988).

37. Wood, R. J. K. , Hutton, S. P. and Schiffrin, D. J., Mass transfer effects of noncavitating seawater on the corrosion of $\mathrm{Cu}$ and 70Cu-30Ni. Corros Sci. 30, 1177 (1990).

38. Faita, G., Fiori, G. and Salvadore, D., Copper behaviour in acid and alkaline brines-I kinetics of anodic dissolution in $0.5 \mathrm{M} \mathrm{NaCl}$ and free-corrosion rates in the presence of oxygen. Corrosion Science, 15, 383 (1975).

39. Lee, H.P. and Nobe, K. , Kinetics and mechanisms of $\mathrm{Cu}$ electrodissolution in chloride media. J. Electrochem Soci.133, 2035 (1986).

40. Braun, M. and Nobe, K., Electrodissolution kinetics of copper in acidic chloride solutions. J. Electrochem. Soci. 126, 1666 (1979).

41. Wagner, A. D., Auger and X-ray photoelectron spectroscopy, in: D. Briggs and M. P. Seath (Ed.), Practical Surface Analysis, Vol. 1, $2^{\text {nd }}$ ed., John Wiley \& Sons New York, p.595 (1990).

(Received 19/2/2014; accepted $26 / 3 / 2014$ ) 


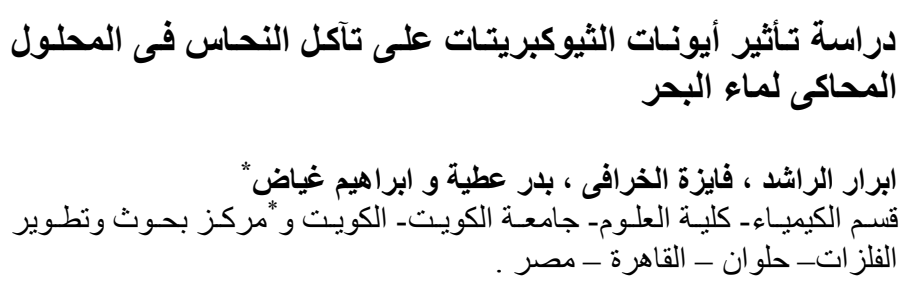

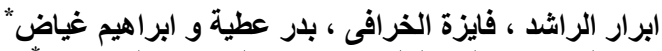

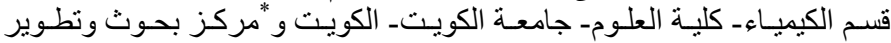

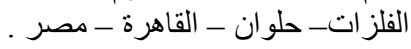

ثيوكبريتات الصوديوم له تأثير قوي على تآكل النحاس في المياه المالحة. أنه يعزز

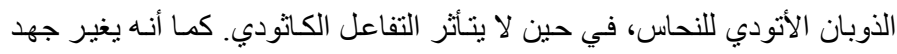

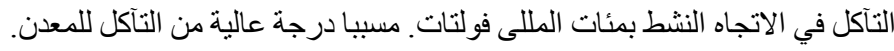

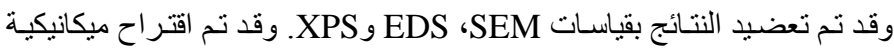

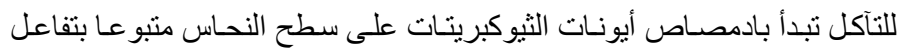
التآكل ينتج كبريتيد النحاس و أيونات الهيدروكبريتيت. 